\title{
Estimated glomerular filtration rate and albuminuria are independent predictors of cardiovascular events and death in type 2 diabetes mellitus: the Fenofibrate Intervention and Event Lowering in Diabetes (FIELD) study
}

\author{
P. L. Drury • R. Ting • D. Zannino • C. Ehnholm • J. Flack • M. Whiting • R. Fassett • \\ J.-C. Ansquer • P. Dixon • T. M. E. Davis • C. Pardy • P. Colman • A. Keech
}

Received: 17 March 2010 / Accepted: 18 June 2010 / Published online: 30 July 2010

(C) Springer-Verlag 2010

\begin{abstract}
Aims/hypothesis We investigated effects of renal function and albuminuria on cardiovascular outcomes in 9,795 lowrisk patients with diabetes in the Fenofibrate Intervention and Event Lowering in Diabetes (FIELD) study.

Methods Baseline and year 2 renal status were examined in relation to clinical and biochemical characteristics. Out-
\end{abstract}

comes included total cardiovascular disease (CVD), cardiac and non-cardiac death over 5 years.

Results Lower estimated GFR (eGFR) vs eGFR $\geq 90 \mathrm{ml} \mathrm{min}^{-1}$ $1.73 \mathrm{~m}^{-2}$ was a risk factor for total CVD events: (HR $[95 \%$ CI] 1.14 [1.01-1.29] for eGFR 60-89 ml min ${ }^{-1} 1.73 \mathrm{~m}^{-2}$; 1.59 [1.28-1.98] for eGFR $30-59 \mathrm{ml} \mathrm{min}^{-1} 1.73 \mathrm{~m}^{-2} ; p<$ 0.001 ; adjusted for other characteristics). Albuminuria in-

P. L. Drury and R. Ting are joint first authors.

\section{P. L. Drury}

Auckland Diabetes Centre,

Auckland, New Zealand

P. L. Drury $(\varangle) \cdot$ R. Ting $(\varangle) \cdot$ D. Zannino $\cdot$ C. Pardy $\cdot$ A. Keech The FIELD Study, NHMRC Clinical Trials Centre,

University of Sydney,

Level 6, Medical Foundation Building, 92-94 Parramatta Road,

Camperdown NSW 2050, Australia

e-mail: pauld@xtra.co.nz

e-mail: rudee.ting@ctc.usyd.edu.au

\section{Ehnholm}

Department of Molecular Medicine, National Public Health Institute, Biomedicum,

Helsinki, Finland

\section{J. Flack}

South Western Clinical School,

University of New South Wales,

Sydney, NSW, Australia

M. Whiting

Flinders Medical Centre,

Adelaide, SA, Australia
R. Fassett

School of Medicine, Royal Brisbane and Women's Hospital, University of Queensland,

Brisbane, QLD, Australia

\section{J.-C. Ansquer}

Nephrologie et Reanimation Metabolique, Centre Hospitalier

Universitaire de Dijon,

Dijon, France

J.-C. Ansquer

Laboratoires Fournier,

Dijon, France

P. Dixon

Diabetes Lifestyle Centre, Palmerston North Hospital,

Palmerston North, New Zealand

T. M. E. Davis

School of Medicine and Pharmacology, Fremantle Hospital,

University of Western Australia,

Fremantle, WA, Australia

\section{P. Colman}

Department of Diabetes and Endocrinology,

Royal Melbourne Hospital,

Melbourne, VIC, Australia 
creased CVD risk, with microalbuminuria and macroalbuminuria increasing total CVD (HR 1.25 [1.01-1.54] and 1.19 [0.76-1.85], respectively; $p=0.001$ for trend) when eGFR $\geq 90 \mathrm{ml} \mathrm{min}{ }^{-1} 1.73 \mathrm{~m}^{-2}$. CVD risk was further modified by renal status changes over the first 2 years. In multivariable analysis, $77 \%$ of the effect of eGFR and $81 \%$ of the effect of albumin:creatinine ratio were accounted for by other variables, principally low HDL-cholesterol and elevated blood pressure.

Conclusions/interpretation Reduced eGFR and albuminuria are independent risk factors for cardiovascular events and mortality rates in a low-risk population of mainly European ancestry. While their independent contributions to CVD risk appear small when other risk factors are considered, they remain excellent surrogate markers in clinical practice because they capture risk related to a number of other characteristics. Therefore, both should be considered when assessing prognosis and treatment strategies in patients with diabetes, and both should be included in risk models.

Keywords Albuminuria - Cardiovascular risk - Diabetes . Diabetic nephropathy $\cdot$ Fenofibrate $\cdot$ Glomerular filtration rate $\cdot$ Risk factors

$\begin{array}{ll}\text { Abbreviations } \\ \text { ACR } & \text { Albumin:creatinine ratio } \\ \text { ADVANCE } & \begin{array}{l}\text { Action in Diabetes and Vascular Disease: } \\ \text { Preterax and Diamicron MR Controlled }\end{array} \\ & \begin{array}{l}\text { Evaluation } \\ \text { Chronic kidney disease }\end{array} \\ \text { CKD } & \begin{array}{l}\text { Cardiovascular disease } \\ \text { CVD }\end{array} \\ \text { eGFR } & \text { Estimated GFR } \\ \text { FIELD } & \begin{array}{l}\text { Fenofibrate Intervention and Event Lowering } \\ \text { in Diabetes }\end{array} \\ \text { MDRD } & \text { Modification of Diet in Renal Disease } \\ \text { UKPDS } & \text { UK Prospective Diabetes Study }\end{array}$

\section{Introduction}

Chronic kidney disease (CKD), based on estimated GFR (eGFR), predicts cardiovascular events in the general population $[1,2]$. Several studies of type 2 diabetes have shown an association between CKD, proteinuria and cardiovascular disease (CVD) prevalence [3] and risk [411]. However, many of these studies were small and did not examine the independent effects of microalbuminuria, macroalbuminuria and eGFR. They were also performed in different patient populations for a variety of outcomes. Recent reports suggest that reduced renal function in people with diabetes, based on eGFR, is more common than previously recognised [12] and that CKD is often not associated with albuminuria, as was previously assumed [13].

Because there have been few investigations of large prospective series of patients with type 2 diabetes, we examined the predictive value of eGFR and albuminuria in the Fenofibrate Intervention and Event Lowering in Diabetes study (FIELD), which was conducted in Australia, New Zealand and Finland [14, 15]. Patients were largely recruited from the community, did not have severe renal impairment and were at relatively low CVD risk. We examined the relationships of baseline renal function and albuminuria with all-cause mortality rates, CVD and nonCVD endpoints and death in this large population of predominantly European origin. Follow-up exceeded 99\% over a median of 5 years. Biochemical analyses were done at central laboratories and an Outcomes Committee using pre-specified definitions adjudicated all endpoints.

\section{Methods}

Study design FIELD was a double-blind placebo-controlled trial of $200 \mathrm{mg}$ once-daily micronised fenofibrate or placebo in 9,795 patients. Details of the design and main outcome measures have been published $[14,15]$. In brief, patients were aged 50 to 75 years old, had type 2 diabetes according to the WHO criteria and mild dyslipidaemia with no immediate indication at study entry for lipid-modifying therapy (inclusion criteria).

Exclusion criteria included elevated plasma creatinine $>130 \mu \mathrm{mol} / \mathrm{l}$, chronic liver or gallbladder disease or a CVD event within the 3 months before recruitment. All patients with National Kidney Foundation CKD stage 5 (eGFR $<15 \mathrm{ml} \mathrm{min}{ }^{-1} 1.73 \mathrm{~m}^{-2}$ ) and stage 4 (eGFR 15$29 \mathrm{ml} \mathrm{m^{-1 }} 1.73 \mathrm{~m}^{-2}$ ), and some with stage 3 (GFR 30$59 \mathrm{ml} \mathrm{min}^{-1} 1.73 \mathrm{~m}^{-2}$ ) of the disease were therefore excluded [16]; only one patient had an entry eGFR below $40 \mathrm{ml} \mathrm{min}^{-1}$ $1.73 \mathrm{~m}^{-2}$ (Fig. 1). For the purposes of classification, patients were placed in one of three groups, with groups 1, 2 and 3 having eGFR ranges of $\geq 90,60-89$ and $30-59 \mathrm{ml} \mathrm{min}^{-1}$ $1.73 \mathrm{~m}^{-2}$ respectively. The entry criteria led to a group with low CVD risk, in which the total mortality rate over 5 years was only $6.9 \%$, an average rate of $1.4 \%$ per year. In a cohort with a mean age of 62 years, this was substantially less than predicted on the basis of other studies [17-19]. Although fenofibrate lowered total cardiovascular events (by $11 \%, p=$ 0.035 ) and various microvascular outcomes [14], there were no significant differences in the primary endpoint (total coronary events) or death (total or cardiovascular related) between the placebo and active treatment groups.

Primary responsibility for all other aspects of patient care, such as control of glycaemia, blood pressure and eye 


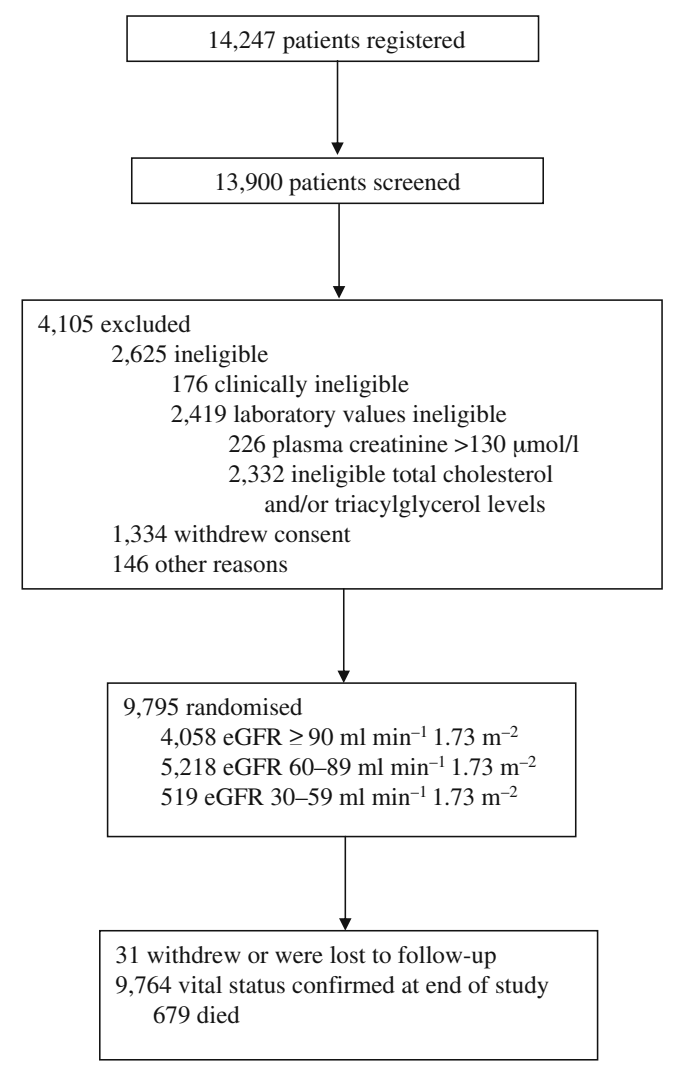

Fig. 1 Enrolment and progress of patients in the FIELD study, grouped by renal function

care, remained with the existing healthcare provider. No central targets were set for these measures.

All patients gave written informed consent to the protocol, which was approved by local and national ethics committees in accordance with the Declaration of Helsinki and Good Clinical Practice guidelines (clinical trials registration no. ISRCTN 64783481).

Outcome ascertainment An outcomes assessment committee, unaware of treatment allocation, adjudicated all deaths and major cardiovascular events (myocardial infarction and stroke). Detailed criteria for these assessments have been published [14]. At study close, mortality status was confirmed for $99.7 \%$ and the primary outcome status for $99.1 \%$ of participants in both groups.

Laboratory measurements Plasma creatinine and urinary albumin:creatinine ratio (ACR) (first morning urine specimen) were recorded as the average of two baseline measurements before the active treatment run-in phase (visits 1 and 3 ). Estimated GFR was calculated using the 4-variable Modification of Diet in Renal Disease study (MDRD) equation: eGFR $\left(\mathrm{ml} \mathrm{min}{ }^{-1} 1.73 \mathrm{~m}^{-2}\right)=186 \times($ plasma creatinine $[\mu \mathrm{mol} / 1]$ divided by 88.4$)^{-1.154} \times(\text { age })^{-0.203} \times(0.742$ if female $) \times(1.212$ if African-American) [20]. All blood and urine samples were analysed in one of two central laboratories in Adelaide, Australia and Helsinki, Finland, both of which participated in a joint quality assurance scheme to ensure consistency between laboratories.

Blood and urinary creatinine measurements were made with alkaline picrate (Hitachi 917; Roche, Mannheim, Germany) in Australia and using Jaffe's photometric method (Cobas Mira; Roche, Basel, Switzerland) in Finland. Urinary albumin was measured by immunoturbidimetric methods (Beckman Array, Beckman-Coulter, Fullerton, CA, USA [in Australia]; Cobas Mira, Roche [in Finland]). The betweenrun coefficients of variation for plasma creatinine and urinary creatinine were $<3 \%$ and $<1.5 \%$, respectively. The between-run coefficients of variation for urinary albumin were $<3 \%$ across the quality control range.

For the purposes of this report, microalbuminuria was defined as $>2.5 \mathrm{mg} / \mathrm{mmol}$ for men and $>3.5 \mathrm{mg} / \mathrm{mmol}$ for women; equivalent values for macroalbuminuria were $>25$ and $>35 \mathrm{mg} / \mathrm{mmol}$, respectively [21].

Statistical analysis All analyses used SAS statistical software (version 9.1, SAS Institute; Cary, NC, USA) or ACCoRD (version 2; Boffin Software, Eastwood, NSW, Australia). Contrast and trend tests for baseline characteristics were analysed using $\chi^{2}$ tests for binary variables, and $t$ tests and ANOVA for continuous variables. If the distribution of the data was not normal, log-transformation was applied to achieve normality. Cox proportional hazards analysis was used to compute hazard ratios and $95 \%$ CIs to assess the effect of albuminuria on mortality outcomes. Although study treatment did not significantly reduce the primary endpoint of CHD events (non-fatal myocardial infarction and coronary death) or death, total CVD events, revascularisation, hospitalisation for acute coronary syndrome and major microvascular outcomes were significantly lowered. For consistency, we analysed all associations between clinical endpoints and baseline data (before the 6week active fenofibrate run-in phase) from all 9,795 patients with adjustment for study treatment group. In adjusted analyses, the log of ACR was used as a continuous covariate and age was included as there was little colinearity between age and eGFR, despite age being part of the MDRD calculation. Cumulative risk curves of the time to first event were calculated using the Kaplan-Meier method. In analyses involving only the placebo group, Kaplan-Meier curves were constructed on the basis of baseline renal status up until 2 years, after which a landmark analysis from this point using updated renal status (remained normal/abnormal or changed) was performed. Additionally, the Harrell-Lee c-index [22] was used to quantify the global performance of the various risk models for CVD that were identified by an exhaustive search Cox regression analysis [23]. This allowed identifi- 
cation of the contribution of other risk variables to the improvement in global performance that was attributable to either eGFR or albuminuria. All statistical inferences use a two-sided $p$ value of 0.05 and are presented unadjusted for multiple comparisons.

\section{Results}

Clinical and metabolic characteristics at baseline The mean age in FIELD was 62 years, with mean diabetes duration of 5 years and $37 \%$ women participants. The median urinary ACR was $1.1 \mathrm{mg} / \mathrm{mmol}$, with $95 \%$ of

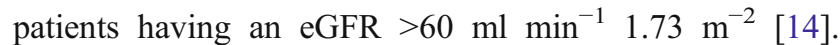
Mean glycaemic control at baseline was near standard target level $\left(\mathrm{HbA}_{1 \mathrm{c}} 6.9 \%\right)$ and blood pressure averaged $140 /$ $84 \mathrm{mmHg}$.

The 519 group 3 patients (eGFR $30-59 \mathrm{ml} \mathrm{min}^{-1}$ $1.73 \mathrm{~m}^{-2}$ ) were more likely than the 9,276 group 1 and 2 patients (eGFR $\geq 60 \mathrm{ml} \mathrm{min}^{-1} 1.73 \mathrm{~m}^{-2}$ ) to be women and older, and to have longer diabetes duration and higher blood pressure (Table 1). They also had significantly higher incidences of retinopathy, microalbuminuria and macroalbuminuria. Compared with groups 1 and 2, group 3 participants had significantly lower fasting serum glucose levels, whereas total cholesterol, triacylglycerol and urine ACR were significantly higher. The rate of ACE inhibitor

Table 1 Clinical and metabolic characteristics of the FIELD population at baseline, by eGFR group

\begin{tabular}{|c|c|c|c|c|c|}
\hline Variable & $\begin{array}{l}\text { Group } 1 \\
\text { eGFR } \geq 90^{\text {a }}\end{array}$ & $\begin{array}{l}\text { Group } 2 \\
\text { eGFR } 60-89^{\text {a }}\end{array}$ & $\begin{array}{l}\text { Group } 3 \\
\text { eGFR } 30-59^{\text {a }}\end{array}$ & All & $p$ value $^{\mathrm{b}}$ \\
\hline$n$ & 4,058 & 5,218 & 519 & 9,795 & \\
\hline Men $(\%)$ & 66 & 62 & 41 & 63 & $<0.001^{\mathrm{e}}$ \\
\hline Age (years) & $60.2(6.7)$ & $63.4(6.7)$ & $66.5(5.9)$ & $62.2(6.9)$ & $<0.001^{\mathrm{e}}$ \\
\hline Duration of diabetes (years) ${ }^{c}$ & $4.8(4.7-5.0)$ & $5.1(4.9-5.2)$ & $6.0(5.5-6.5)$ & $5.0(4.9-5.1)$ & $<0.001^{\mathrm{e}}$ \\
\hline \multicolumn{6}{|l|}{ BMI $\left(\mathrm{kg} / \mathrm{m}^{2}\right)^{\mathrm{c}}$} \\
\hline Women & $32.2(31.9-32.5)$ & $31.2(31.0-31.5)$ & $31.5(30.9-32.2)$ & $31.6(31.4-31.8)$ & 0.7 \\
\hline Men & $29.7(29.5-29.9)$ & $29.1(29.0-29.3)$ & $29.2(28.6-29.8)$ & $29.4(29.3-29.5)$ & 0.6 \\
\hline Systolic BP (mmHg) & $139(15)$ & $141(15)$ & $144(17)$ & $141(15)$ & $<0.001^{\mathrm{e}}$ \\
\hline Current smoker (\%) & 12 & 8 & 7 & 9 & $0.05^{\mathrm{e}}$ \\
\hline Ex-smoker $(\%)$ & 52 & 50 & 42 & 50 & $<0.001^{\mathrm{e}}$ \\
\hline Retinopathy (\%) & 7 & 9 & 13 & 8 & $<0.001^{\mathrm{e}}$ \\
\hline Prior cancers $(\%)$ & 6 & 8 & 12 & 7 & $<0.001^{\mathrm{e}}$ \\
\hline \multicolumn{6}{|l|}{ Laboratory data } \\
\hline Fasting PG $(\mathrm{mmol} / \mathrm{l})^{\mathrm{c}}$ & $8.8(8.7-8.8)$ & $8.5(8.4-8.5)$ & $8.2(8.0-8.4)$ & $8.6(8.5-8.6)$ & $<0.001^{\mathrm{e}}$ \\
\hline Total cholesterol $(\mathrm{mmol} / \mathrm{l})$ & $5.02(5.00-5.04)$ & $5.04(5.02-5.06)$ & $5.11(5.05-5.17)$ & $5.04(5.02-5.05)$ & $0.02^{\mathrm{d}}$ \\
\hline HDL-cholesterol $(\mathrm{mmol} / \mathrm{l})^{\mathrm{c}}$ & $1.07(1.06-1.07)$ & $1.07(1.06-1.08)$ & $1.06(1.03-1.08)$ & $1.07(1.06-1.07)$ & 0.2 \\
\hline LDL-cholesterol (mmol/1) & $3.06(3.04-3.08)$ & $3.07(3.05-3.09)$ & $3.07(3.02-3.13)$ & $3.07(3.05-3.08)$ & 0.8 \\
\hline Triacylglycerol $(\mathrm{mmol} / \mathrm{l})^{\mathrm{c}}$ & $1.76(1.74-1.78)$ & $1.79(1.77-1.81)$ & $1.91(1.85-1.98)$ & $1.78(1.77-1.80)$ & $<0.001^{\mathrm{e}}$ \\
\hline $\mathrm{HbA}_{1 \mathrm{c}}(\%)^{\mathrm{c}}$ & $7.0(6.9-7.0)$ & $6.9(6.9-6.9)$ & $7.0(6.9-7.1)$ & $6.9(6.9-7.0)$ & 0.2 \\
\hline Urine ACR (mg/mmol) & $1.1[0.6-2.8]$ & $1.1[0.6-2.8]$ & $1.9[0.8-8.7]$ & $1.1[0.6-3.0]$ & $<0.001^{\mathrm{e}}$ \\
\hline Normal ACR, $n(\%)^{\mathrm{f}}$ & $3,026(75)$ & $3,927(75)$ & 307 (59) & $7,260(74)$ & $<0.001^{\mathrm{e}}$ \\
\hline Microalbuminuria, $n(\%)$ & $890(22)$ & $1,068(21)$ & $146(28)$ & $2,104(22)$ & $<0.001$ \\
\hline Macroalbuminuria, $n(\%)$ & $126(3)$ & $213(4)$ & $65(13)$ & 404 (4) & $<0.001^{\mathrm{e}}$ \\
\hline \multicolumn{6}{|l|}{ Baseline medication } \\
\hline Use of RAAS inhibitors (\%) & 37 & 38 & 55 & 39 & $<0.001^{\mathrm{e}}$ \\
\hline
\end{tabular}

Values are mean $(\mathrm{SD})$, mean $(95 \% \mathrm{CI})$ or median [interquartile range] unless otherwise indicated

${ }^{\mathrm{a}} \mathrm{In} \mathrm{ml} \min ^{-1} 1.73 \mathrm{~m}^{-2}$

${ }^{\mathrm{b}}$ Compares eGFR 30-59 group (stage 3) with other two combined

${ }^{\mathrm{c}}$ Distribution skewed, so analyses used log-transformed data, reported as geometric means $(95 \% \mathrm{CI})$

${ }^{\mathrm{d}} p<0.05$ for trend; ${ }^{\mathrm{e}} p<0.001$ for trend

${ }^{\mathrm{f}}$ Baseline albuminuria levels not available for $27(0.3 \%)$ patients

$\mathrm{PG}$, plasma glucose; RAAS, renin-angiotensin-aldosterone system 
or angiotensin-receptor blocker use was also higher in this group. At baseline, 2,508 (26\%) patients had albuminuria and 5,737 (59\%) had eGFR 30-89 ml min $\mathrm{min}^{-1} 1.73 \mathrm{~m}^{-2}$. Only a small number had macroalbuminuria $(404,4 \%)$ or eGFR $30-59 \mathrm{ml} \mathrm{min}^{-1} 1.73 \mathrm{~m}^{-2}(519,5 \%)$, and no patients had eGFR $<30 \mathrm{ml} \mathrm{min}{ }^{-1} 1.73 \mathrm{~m}^{-2}$. These measures of kidney disease were largely independent, with almost $80 \%$ of those with renal impairment being normoalbuminuric and $40 \%$ of those with abnormal albuminuria having eGFR $>90 \mathrm{ml} \mathrm{min}{ }^{-1} 1.73 \mathrm{~m}^{-2}$ (Correlation coefficient $r=-0.05$; $p<0.001$ ) (Table 1).

Clinical outcomes for participants with a reduced eGFR Total CVD and coronary event rates during the study were progressively higher with greater baseline renal impairment, as were non-fatal stroke and myocardial infarction (Table 2). Death rates due to CVD, CHD, stroke, non-CHD causes, non-CVD causes, cancer and all causes also followed the same trend. When adjusted for age, sex and allocated study treatment, the higher risk remained significant for CVD and CHD events, CVD or non-CHD death, and death from all causes (Table 3). Adjusted for the six outcomes, there was no evidence of any treatment $\times$ subgroup interaction. When risk in a multivariable model was adjusted additionally for a range of clinical and biochemical baseline characteristics, rates of total CVD events, CVD death, non-coronary death and death from all causes remained significantly higher with greater renal impairment (Table 3). These patterns were similar within each level of urinary albumin group (Tables 4 and 5, Fig. 2a). The hazard ratio for eGFR $<60 \mathrm{ml} \mathrm{min}^{-1} 1.73 \mathrm{~m}^{-2}$ vs eGFR $\geq 60 \mathrm{ml} \mathrm{min}^{-1} 1.73 \mathrm{~m}^{-2}$ was $1.44(95 \%$ CI 1.18 1.76; $p<0.001$ ) for total CVD, 2.00 (95\% CI 1.41-2.84; $p<$ 0.001 ) for CVD death and 1.66 (95\% CI 1.30-2.11; $p<$ 0.001 ) for overall mortality. No eGFR group had significantly greater CVD risk reduction than any other group from treatment with fenofibrate.

In multivariable analysis (placebo group), eGFR remained an independent risk factor for CVD, exclusive of age and sex $(p=0.0006)$. Nevertheless, $77 \%$ of its univariable association with CVD risk was accounted for by the other variables in the full model, most importantly, HDL-cholesterol alone (about 39\%), and together with systolic blood pressure (about 71\%).

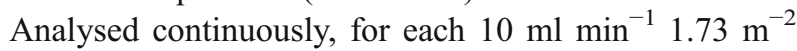
lower baseline eGFR, the risk of a CVD event, CVD death or death from all causes was inversely linearly related, being $6 \%, 10 \%$ and $4 \%$ higher over the subsequent 5 years $(p<0.001, p=0.01$ and $p=0.08$, respectively).

Among placebo patients, those with eGFR $<60 \mathrm{ml} \mathrm{min}^{-1}$ $1.73 \mathrm{~m}^{-2}$ at baseline and year 2 had the greatest total CVD risk, while those with eGFR $\geq 60 \mathrm{ml} \mathrm{min}^{-1} 1.73 \mathrm{~m}^{-2}$ over

Table 2 Cardiovascular outcomes, by eGFR group, in patients in the FIELD study

\begin{tabular}{|c|c|c|c|c|}
\hline Variable & $\begin{array}{l}\text { Group } 1 \\
\geq 90^{\mathrm{a}}\end{array}$ & $\begin{array}{l}\text { Group } 2 \\
60-89^{\mathrm{a}}\end{array}$ & $\begin{array}{l}\text { Group } 3 \\
30-59^{\mathrm{a}}\end{array}$ & All \\
\hline$n$ & 4,058 & 5,218 & 519 & 9,795 \\
\hline \multicolumn{5}{|l|}{ Cardiovascular events $(n=1,295)$} \\
\hline Any & $10.8(9.9-11.8)$ & $14.1(13.2-15.1)$ & $22.5(18.9-26.1)$ & $13.2(12.6-13.9)$ \\
\hline CHD event & $4.4(3.8-5.1)$ & $6.0(5.4-6.7)$ & $9.3(7.1-12.2)$ & $5.5(5.1-6.0)$ \\
\hline Any stroke & $2.7(2.2-3.2)$ & $3.4(3.0-3.9)$ & $8.3(5.9-10.7)$ & $3.4(3.0-3.8)$ \\
\hline \multicolumn{5}{|l|}{ Deaths $(n=679)$} \\
\hline Cardiovascular & $2.0(1.5-2.4)$ & $2.7(2.3-3.2)$ & $8.5(6.1-10.9)$ & $2.7(2.4-3.0)$ \\
\hline CHD & $1.5(1.2-2.0)$ & $2.3(1.9-2.7)$ & $3.9(2.5-6.0)$ & $2.1(1.8-2.4)$ \\
\hline Stroke & $0.2(0.1-0.4)$ & $0.2(0.1-0.4)$ & $3.0(1.8-4.9)$ & $0.4(0.3-0.5)$ \\
\hline Non-CHD & $3.8(3.2-4.4)$ & $5.0(4.4-5.6)$ & $12.1(9.3-14.9)$ & $4.9(4.4-5.3)$ \\
\hline Non-cardiovascular & $3.4(2.8-4.0)$ & $4.5(3.9-5.0)$ & $7.5(5.5-10.2)$ & $4.2(3.8-4.6)$ \\
\hline Cancer & $2.7(2.2-3.2)$ & $3.4(2.9-3.9)$ & $5.5(3.8-7.8)$ & $3.2(2.9-3.6)$ \\
\hline Non-cardiovascular, non-cancer & $0.7(0.4-0.9)$ & $1.1(0.8-1.4)$ & $2.1(0.9-3.4)$ & $1.0(0.8-1.2)$ \\
\hline Any cause & $5.4(4.7-6.1)$ & $7.2(6.5-7.9)$ & $16.4(13.4-19.8)$ & $6.9(6.4-7.4)$ \\
\hline \multicolumn{5}{|l|}{ Non-fatal events $(n=633)$} \\
\hline Stroke & $2.5(2.0-3.0)$ & $3.2(2.8-3.7)$ & $5.5(3.8-7.8)$ & $3.1(2.7-3.4)$ \\
\hline Myocardial infarction & $2.9(2.4-3.5)$ & $4.1(3.6-4.7)$ & $5.8(3.8-7.8)$ & $3.7(3.4-4.1)$ \\
\hline
\end{tabular}

Values are per cent $(95 \% \mathrm{CI})$ of participants experiencing an event, unless otherwise indicated

$p \leq 0.002$ for all outcomes in trend tests across levels of eGFR; $p \leq 0.01$ for all outcomes in comparisons of eGFR 30-59 (group 3) with the other two groups combined

${ }^{\mathrm{a}} \mathrm{In} \mathrm{ml} \mathrm{min}^{-1} 1.73 \mathrm{~m}^{-2}$ 
Table 3 Hazard ratios $\left(95 \%\right.$ CI) for outcomes, by eGFR group ${ }^{\mathrm{a}}$, in patients in the FIELD study ${ }^{\mathrm{b}}$

\begin{tabular}{|c|c|c|c|c|}
\hline Variable & $\begin{array}{l}\text { Group } 1 \\
\geq 90^{\mathrm{c}}\end{array}$ & $\begin{array}{l}\text { Group } 2 \\
60-89^{\mathrm{d}}\end{array}$ & $\begin{array}{l}\text { Group } 3 \\
30-59^{\mathrm{e}}\end{array}$ & $p$ value \\
\hline$n$ & 4,058 & 5,218 & 519 & \\
\hline \multicolumn{5}{|l|}{ Cardiovascular event } \\
\hline Adjusted for age, sex and treatment & 1.00 & $1.15(1.02-1.30)$ & $2.01(1.62-2.48)$ & $<0.001$ \\
\hline 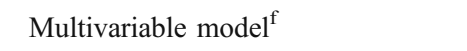 & 1.00 & $1.14(1.01-1.29)$ & $1.59(1.28-1.98)$ & $<0.001$ \\
\hline \multicolumn{5}{|l|}{ CHD event } \\
\hline Adjusted for age, sex and treatment & 1.00 & $1.14(0.94-1.38)$ & $1.76(1.26-2.45)$ & 0.004 \\
\hline 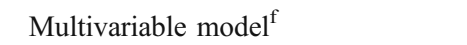 & 1.00 & $1.13(0.94-1.37)$ & $1.27(0.90-1.79)$ & 0.3 \\
\hline \multicolumn{5}{|l|}{ Cardiovascular death } \\
\hline Adjusted for age, sex and treatment & 1.00 & $1.08(0.81-1.42)$ & $3.09(2.09-4.57)$ & $<0.001$ \\
\hline Multivariable $\operatorname{model}^{\mathrm{f}}$ & 1.00 & $1.05(0.79-1.40)$ & $2.08(1.39-3.12)$ & $<0.001$ \\
\hline \multicolumn{5}{|l|}{ Non-coronary death } \\
\hline Adjusted for age, sex and treatment & 1.00 & $0.99(0.81-1.22)$ & $2.20(1.62-3.00)$ & $<0.001$ \\
\hline 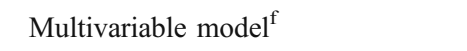 & 1.00 & $1.01(0.82-1.24)$ & $1.97(1.43-2.70)$ & $<0.001$ \\
\hline \multicolumn{5}{|l|}{ Cancer death } \\
\hline Adjusted for age, sex and treatment & 1.00 & $0.95(0.74-1.21)$ & $1.41(0.92-2.16)$ & 0.15 \\
\hline 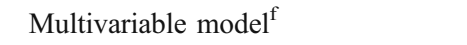 & 1.00 & $0.96(0.75-1.23)$ & $1.28(0.83-1.98)$ & 0.4 \\
\hline \multicolumn{5}{|l|}{ Death from any cause } \\
\hline Adjusted for age, sex and treatment & 1.00 & $1.02(0.86-1.21)$ & $2.08(1.60-2.71)$ & $<0.001$ \\
\hline 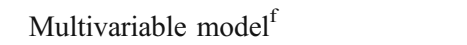 & 1.00 & $1.03(0.86-1.22)$ & $1.69(1.29-2.22)$ & $<0.001$ \\
\hline
\end{tabular}

${ }^{\text {a }}$ Group with eGFR $\geq 90 \mathrm{ml} \mathrm{min}{ }^{-1} 1.73 \mathrm{~m}^{-2}$ is the reference group

${ }^{b}$ Tests of interaction between eGFR group and treatment were non-significant except for CVD death

${ }^{\mathrm{c}}$ Median eGFR ( $\mathrm{ml} \mathrm{min}{ }^{-1} 1.73 \mathrm{~m}^{-2}$ ): 101.7 (95.3-111.2)

${ }^{\mathrm{d}}$ Median eGFR ( $\left.\mathrm{ml} \mathrm{min}{ }^{-1} 1.73 \mathrm{~m}^{-2}\right): 78.4(72.0-84.2)$

${ }^{\mathrm{e}}$ Median eGFR ( $\left.\mathrm{ml} \mathrm{min}{ }^{-1} 1.73 \mathrm{~m}^{-2}\right): 55.5$ (51.6-58.0)

${ }^{\mathrm{f}}$ Multivariable model adjusted for age, sex, duration of diabetes, smoking status, BMI, systolic BP, HbA $1 \mathrm{c}$, HDL-cholesterol, LDL-cholesterol, triacylglycerol, diabetic retinopathy, treatment with ACE inhibitors or angiotensin-receptor blockers, treatment group and log of the ACR (as a continuous covariate)

the same timeframe had the least $(p<0.001)$. In participants whose eGFR status changed between the two time-points, CVD risk appeared to be intermediate, with a change in eGFR from $\geq 60 \mathrm{ml} \mathrm{m^{-1 }} 1.73 \mathrm{~m}^{-2}$ at baseline to $<60 \mathrm{ml} \mathrm{min}{ }^{-1} 1.73 \mathrm{~m}^{-2}$ at year 2 showing greater risk than the converse, although this was not statistically significant $(p=0.76)$ (Fig. 3a). The risk of a CVD event after progressing to eGFR $<30 \mathrm{ml} \mathrm{min}^{-1} 1.73 \mathrm{~m}^{-2}$ vs maintaining eGFR $\geq 30 \mathrm{ml} \mathrm{min}^{-1} 1.73 \mathrm{~m}^{-2}$ was not significantly different ( $13.0 \%$ vs $13.7 \%$, respectively), but only 69 placebo participants deteriorated to this level at any time, and only seven prior to their first CVD event.

Clinical outcomes for participants with albuminuria The effect of albuminuria was examined before and after adjustment for a variety of baseline characteristics. Across all three eGFR groups, hazard ratios for patients with albuminuria were consistently higher than for those without (Fig. 2a, Table 4). Even after adjustment for multiple known risk factors, there were significant, graded hazard ratios for microalbuminuria and macroalbuminuria across almost all levels of eGFR (Tables 4 and 5), except for cancer death. For example, group 3 patients with microalbuminuria or macroalbuminuria had a higher risk of a coronary event, CVD death, death from all causes or a CVD event than group 3 normoalbuminuric patients $(p<$ 0.05 for trend for all) (Table 4). The CVD risk for patients with eGFR $>90 \mathrm{ml} \mathrm{min}{ }^{-1} 1.73 \mathrm{~m}^{-2}$ and albuminuria was almost the same as for those who were normoalbuminuric with eGFR $30-59 \mathrm{ml} \mathrm{min}^{-1} 1.73 \mathrm{~m}^{-2}$ and was significantly higher than for those who were normoalbuminuric without renal impairment. The highest risk category was group 3 patients with co-existent albuminuria (Fig. 2a, b). Subgroup analyses according to albuminuria level overall failed to show any significant treatment $\times$ subgroup interactions.

The pooled hazard ratio for all albuminuria vs normoalbuminuria was $1.31(95 \%$ CI $1.16-1.48 ; p<0.001)$ for total CVD and $1.46(95 \%$ CI $1.24-1.72 ; p<0.001)$ for death, both after baseline adjustment. Analysed continuously, for each $5 \mathrm{mg} / \mathrm{mmol}$ higher urinary ACR, the risk of a CVD 
Table 4 Adjusted hazard ratios $(95 \% \mathrm{CI})$ for primary and secondary outcomes, by eGFR and albuminuria ${ }^{\mathrm{a}, \mathrm{b}}$

\begin{tabular}{|c|c|c|c|c|c|c|}
\hline \multirow[t]{2}{*}{ Variable } & \multirow[t]{2}{*}{ Total $(n)$} & \multirow{2}{*}{$\begin{array}{l}\text { Group } 1 \\
\geq 90^{\mathrm{c}}\end{array}$} & \multirow{2}{*}{$\begin{array}{l}\text { Group } 2 \\
60-89^{c}\end{array}$} & \multirow{2}{*}{$\begin{array}{l}\text { Group } 3 \\
30-59^{c}\end{array}$} & \multicolumn{2}{|c|}{$p$ value for trend ${ }^{\mathrm{d}}$} \\
\hline & & & & & Albuminuria & eGFR \\
\hline$n$ & & 4,042 & 5,208 & 518 & & \\
\hline Cardiovascular events & 1,290 & & & & & \\
\hline No albuminuria & 800 & 1.00 & $1.11(0.95-1.29)$ & $1.63(1.20-2.20)$ & 0.001 & $<0.001$ \\
\hline Microalbuminuria & 382 & $1.25(1.01-1.54)$ & $1.43(1.18-1.72)$ & $1.94(1.37-2.73)$ & & \\
\hline Macroalbuminuria & 108 & $1.19(0.76-1.85)$ & $1.77(1.33-2.36)$ & $2.30(1.48-3.55)$ & & \\
\hline CHD events & 541 & & & & & \\
\hline No albuminuria & 311 & 1.00 & $1.07(0.84-1.36)$ & $1.20(0.72-2.01)$ & $<0.001$ & 0.13 \\
\hline Microalbuminuria & 163 & $1.26(0.91-1.76)$ & $1.47(1.10-1.96)$ & $1.87(1.12-3.13)$ & & \\
\hline Macroalbuminuria & 67 & $2.00(1.15-3.47)$ & $2.65(1.81-3.89)$ & $2.43(1.28-4.59)$ & & \\
\hline Cardiovascular deaths & 266 & & & & & \\
\hline No albuminuria & 137 & 1.00 & $1.17(0.80-1.72)$ & $2.36(1.29-4.31)$ & $<0.001$ & 0.004 \\
\hline Microalbuminuria & 87 & $1.73(1.08-2.77)$ & $1.38(0.88-2.15)$ & $2.96(1.59-5.51)$ & & \\
\hline Macroalbuminuria & 42 & $1.89(0.83-4.27)$ & $2.59(1.49-4.50)$ & $5.26(2.73-10.15)$ & & \\
\hline Non-CHD deaths & 475 & & & & & \\
\hline No albuminuria & 292 & 1.00 & $1.08(0.83-1.40)$ & $2.40(1.58-3.64)$ & 0.02 & 0.004 \\
\hline Microalbuminuria & 145 & $1.63(1.15-2.29)$ & $1.42(1.04-1.96)$ & $2.19(1.29-3.73)$ & & \\
\hline Macroalbuminuria & 38 & $1.52(0.70-3.31)$ & $1.52(0.90-2.57)$ & $3.83(2.11-6.98)$ & & \\
\hline Cancer deaths & 315 & & & & & \\
\hline No albuminuria & 202 & 1.00 & $1.01(0.75-1.36)$ & $1.44(0.81-2.57)$ & 0.32 & 0.55 \\
\hline Microalbuminuria & 93 & $1.42(0.94-2.15)$ & $1.26(0.86-1.84)$ & $1.71(0.87-3.38)$ & & \\
\hline Macroalbuminuria & 20 & $1.54(0.61-3.87)$ & $1.24(0.64-2.40)$ & $1.58(0.57-4.40)$ & & \\
\hline Death from any cause & 677 & & & & & \\
\hline No albuminuria & 397 & 1.00 & $1.10(0.88-1.37)$ & $1.93(1.32-2.82)$ & $<0.001$ & 0.005 \\
\hline Microalbuminuria & 209 & $1.60(1.20-2.14)$ & $1.36(1.04-1.78)$ & $2.25(1.46-3.46)$ & & \\
\hline Macroalbuminuria & 71 & $1.71(0.96-3.06)$ & $2.10(1.44-3.05)$ & $3.48(2.12-5.73)$ & & \\
\hline
\end{tabular}

${ }^{a}$ Group with eGFR $\geq 90$ and no albuminuria is the reference group; baseline albuminuria levels not available for $27(0.3 \%)$ patients

${ }^{\mathrm{b}}$ Baseline adjustment for age, sex, duration of diabetes, smoking, BMI, systolic BP, $\mathrm{HbA}_{1 \mathrm{c}}$, HDL-cholesterol, LDL-cholesterol, triacylglycerol, retinopathy, renin-angiotensin-aldosterone inhibition and treatment group

${ }^{\mathrm{c}} \mathrm{In} \mathrm{ml} \mathrm{min}^{-1} 1.73 \mathrm{~m}^{-2}$

${ }^{\mathrm{d}}$ Trend tests across increasing levels of albuminuria are stratified by eGFR group and vice versa

event, CVD death or death from all causes was inversely linearly related, being $1 \%, 3 \%$ and $3 \%$ higher over the subsequent 5 years, respectively (all $p<0.002$ ).

Among placebo patients, those with albuminuria at baseline and year 2 had the greatest total CVD risk, while those who were normoalbuminuric over the same timeframe had the least risk (Fig. 3b). In participants whose albuminuria status changed between these two time-points, the CVD risk was also modified. In them, the development of albuminuria from baseline to year 2 increased risk compared with those who remained normoalbuminuric $(p=$ 0.006 ), whereas regression from albuminuria to normoalbuminuria carried significantly lower CVD risk compared with its persistence $(p=0.01)$.

In multivariable analysis, albuminuria remained an independent risk factor for CVD $(p=0.0008)$. Similar to eGFR, about $81 \%$ of its univariate association with CVD risk was accounted for by the other variables in the full model. Again, the most important of these was HDLcholesterol alone (about 37\%) and together with systolic blood pressure (about 70\%).

\section{Discussion}

This study confirms and extends previous findings of independent relationships between reduced baseline eGFR, albuminuria and subsequent CVD event rates to a large low-risk, mainly Europid population with type 2 diabetes. The FIELD cohort was between CKD stages 1 to 3 at baseline, with few having prior myocardial infarction, yet there was a strong progressive relationship between lower GFR and death from all causes, particularly CVD-related. This persisted despite correction for 
Table 5 Counts and percentages of events per eGFR group
Percentages are of the number of people as defined by eGFR and albuminuria grouping as listed in Table 1

${ }^{\mathrm{a}}$ In $\mathrm{ml} \mathrm{min}^{-1} 1.73 \mathrm{~m}^{-2}$

\begin{tabular}{|c|c|c|c|c|c|c|c|}
\hline \multirow[t]{3}{*}{ Type of event (no. of events) } & \multirow[t]{3}{*}{ Total $(n)$} & \multicolumn{2}{|c|}{ Group 1} & \multicolumn{2}{|c|}{ Group 2} & \multicolumn{2}{|c|}{ Group 3} \\
\hline & & \multicolumn{2}{|l|}{$\geq 90^{\mathrm{a}}$} & \multicolumn{2}{|c|}{$60-89^{\mathrm{a}}$} & \multicolumn{2}{|c|}{$30-59^{\mathrm{a}}$} \\
\hline & & $n$ & $\%$ & $n$ & $\%$ & $n$ & $\%$ \\
\hline Cardiovascular event & 1,290 & & & & & & \\
\hline No albuminuria & 800 & 284 & 9.4 & 463 & 11.8 & 53 & 17.3 \\
\hline Microalbuminuria & 382 & 131 & 14.7 & 211 & 19.8 & 40 & 27.4 \\
\hline Macroalbuminuria & 108 & 22 & 17.5 & 63 & 29.6 & 23 & 35.4 \\
\hline CHD event & 541 & & & & & & \\
\hline No albuminuria & 311 & 112 & 3.7 & 181 & 4.6 & 18 & 5.9 \\
\hline Microalbuminuria & 163 & 53 & 6.0 & 92 & 8.6 & 18 & 12.3 \\
\hline Macroalbuminuria & 67 & 15 & 11.9 & 41 & 19.2 & 11 & 16.9 \\
\hline Cardiovascular death & 266 & & & & & & \\
\hline No albuminuria & 137 & 42 & 1.4 & 79 & 2.0 & 16 & 5.2 \\
\hline Microalbuminuria & 87 & 31 & 3.5 & 41 & 3.8 & 15 & 10.3 \\
\hline Macroalbuminuria & 42 & 7 & 5.6 & 22 & 10.3 & 13 & 20.0 \\
\hline Non-CHD death & 475 & & & & & & \\
\hline No albuminuria & 292 & 94 & 3.1 & 165 & 4.2 & 33 & 10.7 \\
\hline Microalbuminuria & 145 & 53 & 6.0 & 75 & 7.0 & 17 & 11.6 \\
\hline Macroalbuminuria & 38 & 7 & 5.6 & 18 & 8.5 & 13 & 20.0 \\
\hline Cancer death & 315 & & & & & & \\
\hline No albuminuria & 202 & 71 & 2.3 & 116 & 3.0 & 15 & 4.9 \\
\hline Microalbuminuria & 93 & 34 & 3.8 & 49 & 4.6 & 10 & 6.8 \\
\hline Macroalbuminuria & 20 & 5 & 4.0 & 11 & 5.2 & 4 & 6.2 \\
\hline Death from any cause & 677 & & & & & & \\
\hline No albuminuria & 397 & 129 & 4.3 & 230 & 5.9 & 38 & 12.4 \\
\hline Microalbuminuria & 209 & 76 & 8.5 & 106 & 9.9 & 27 & 18.5 \\
\hline Macroalbuminuria & 71 & 13 & 10.3 & 39 & 18.3 & 19 & 29.2 \\
\hline
\end{tabular}

age and multiple known related factors, with large variations in associated risk. The correlation of the same outcomes with albuminuria within each eGFR group confirmed its independent value as a CVD risk marker, even as a categorical variable.

The FIELD results also demonstrate that changing renal status over several years further modifies subsequent CVD risk. These novel findings underscore the clinical importance of early initiation of treatments known to prevent the renal complications of diabetes in patients considered to be at risk, as well as initiation of efforts to reverse existing renal disease.

Although eGFR and albuminuria are significant independent CVD risk predictors, their contribution to overall risk, when other cardiovascular risk factors are taken into account, is diminished. However, as simple risk markers in clinical practice, they are highly predictive with a doubling of CVD risk in patients with eGFR 30-59 $\mathrm{ml} \mathrm{min}^{-1}$ $1.73 \mathrm{~m}^{-2}$ or macroalbuminuria compared with normal renal status. Thus, eGFR and albuminuria remain excellent surrogate markers of CVD risk because they capture risk related to a number of other characteristics. It is well documented that much of their association with CVD might be explained by differences in HDL-cholesterol and systolic blood pressure, with low HDL-cholesterol and raised blood pressure being both causes and effects of worsening renal disease [24-26].

A reduced GFR may be associated with an increased level of non-traditional CVD risk factors that are frequently not assessed in many studies. Non-traditional factors such as hyperhomocysteinaemia, oxidant stress and elevated inflammatory markers are associated with atherosclerosis and may be additional contributors to the high incidence of CVD in CKD [27, 28]. Reduced GFR may also be a marker of severity or of undiagnosed vascular disease, and may itself be a risk factor for progression of ventricular remodelling and cardiac dysfunction beyond its direct effects on blood pressure [29]. Furthermore, recent studies suggest that participants with reduced GFR are less likely to receive medications or therapies including cardio-protective ones, compared with those with preserved GFR [30-32].

Albuminuria may reflect generalised endothelial dysfunction and increased vascular permeability, or abnormal- 
a
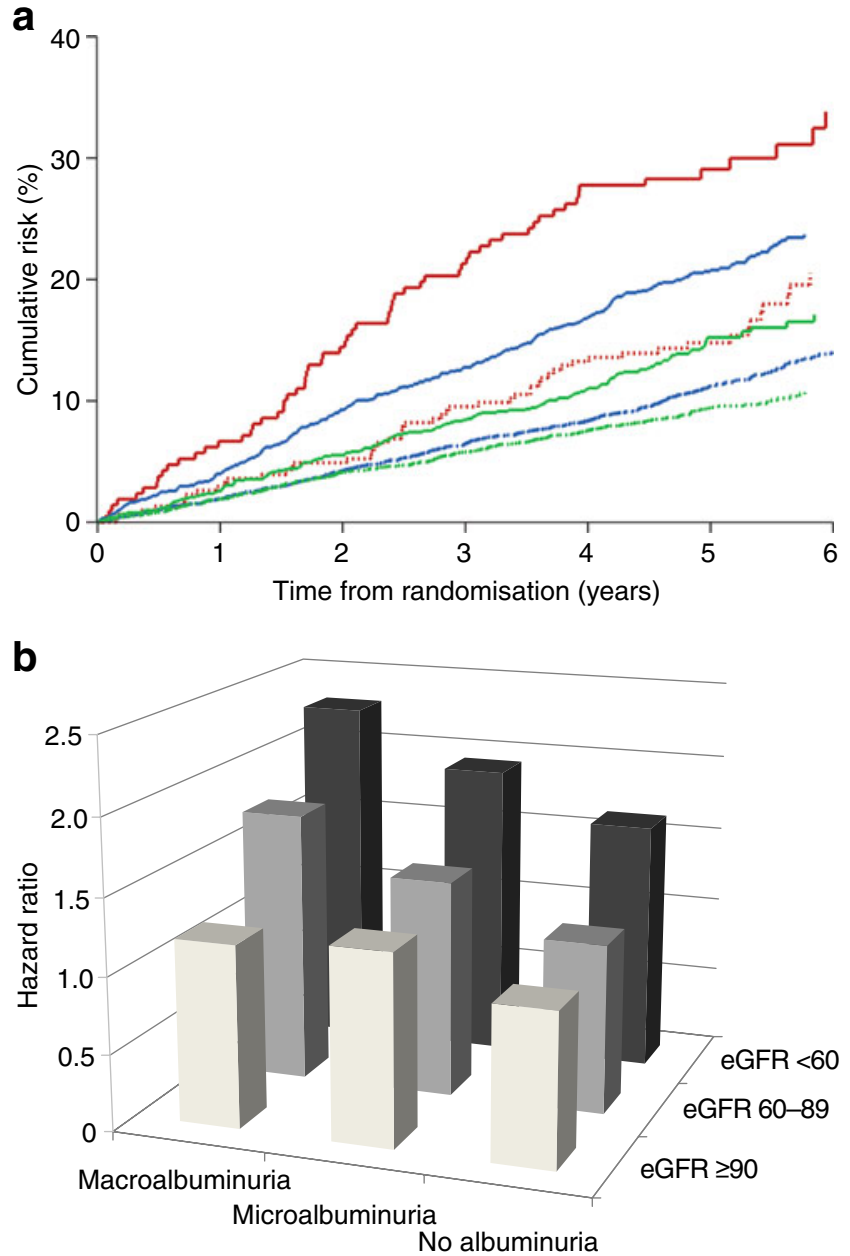

Fig. 2 a Cardiovascular risk for eGFR groups, according to presence of baseline albuminuria. Continuous lines indicate albuminuria present, dotted lines indicate no albuminuria. Red, eGFR 30$59 \mathrm{ml} \mathrm{min}{ }^{-1} 1.73 \mathrm{~m}^{-2}$; blue, eGFR 60-89 $\mathrm{ml} \mathrm{min}^{-1} 1.73 \mathrm{~m}^{-2}$; green, eGFR $\geq 90 \mathrm{ml} \mathrm{min}^{-1} 1.73 \mathrm{~m}^{-2}$. b Cardiovascular risk of eGFR groups, according to presence or not of baseline micro- and macroalbuminuria

ities in the coagulation and fibrinolytic systems. It is also associated with elevated inflammatory markers and may denote greater severity of end-organ damage [33-35]. Therefore, even after adjusting for the presence of CVD, patients with albuminuria are likely to have more severe disease [29].

In CKD atherosclerosis and large-vessel remodelling (arteriosclerosis) are common. Atherosclerosis can lead to ischaemic heart disease, while arteriosclerosis results in pressure overload leading to cardiomyopathy. Furthermore, anaemia, fluid overload and medical arterio-venous fistulas associated with CKD result in volume overload leading to left ventricular dilatation [29]. Most of the traditional CVD risk factors, such as older age, hypertension and low HDLcholesterol [36], are highly prevalent in CKD and may have a qualitatively and quantitatively different risk relationship with CVD in CKD compared with the general population [37].
In recent years, three large studies have identified eGFR and albuminuria as baseline risk factors for death in type 2 diabetes in a variety of racial and ethnic groups. Each of
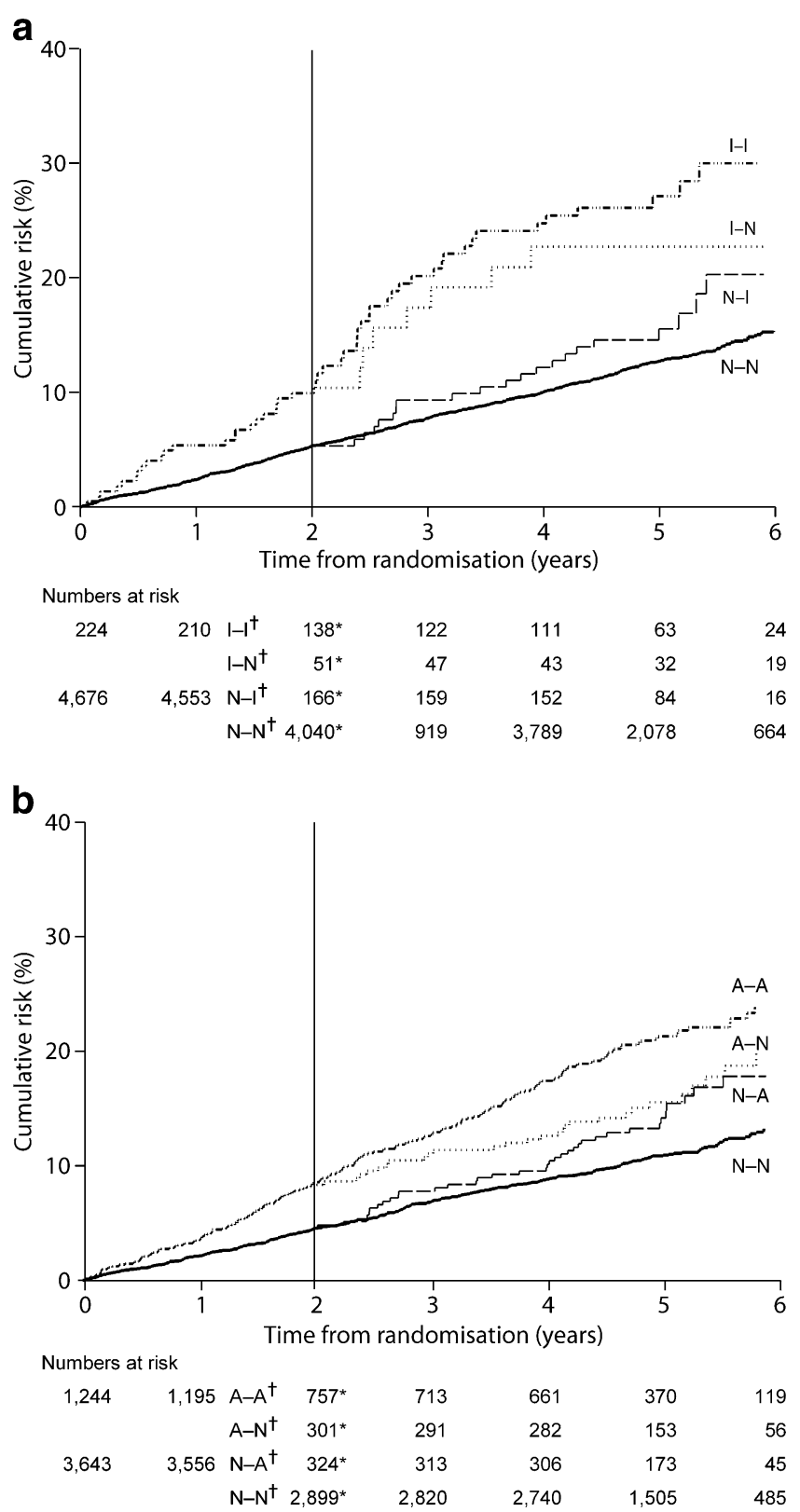

Fig. 3 Proportion of patients in the placebo group with CVD events by status at baseline and after year 2 for (a) eGFR defined as normal $\left(\mathrm{N}: \geq 60 \mathrm{ml} \mathrm{min}^{-1} 1.73 \mathrm{~m}^{-2}\right.$ ) and impaired (I: $<60 \mathrm{ml} \mathrm{min}^{-1} 1.73 \mathrm{~m}^{-2}$ ) (solid lines, N-N; dashed line, N-I; dotted line, I-N; dotted-dashed line, I-I); and (b) albuminuria, defined as albuminuric, i.e. micro- or macroalbuminuric (A), and normoalbuminuric $(\mathrm{N})$ ( solid lines, $\mathrm{N}-\mathrm{N}$; dashed line, N-A; dotted line, A-N; dotted-dashed line, A-A). *eGFR and albuminuria data at year 2 were not available for 250 and 236 patients, respectively. Curve annotations (see the Methods) denote: status at baseline and status at year 2. For example I-N: eGFR $<60 \mathrm{ml} \mathrm{min}{ }^{-1} 1.73 \mathrm{~m}^{-2}$ at baseline and $\geq 60 \mathrm{ml} \mathrm{min}^{-1} 1.73 \mathrm{~m}^{-2}$ at year 2; A-A: albuminuric at baseline and year $2 . \mathbf{a}^{\dagger} p=0.33$ for I-I vs I-N, logrank test; $p=0.07$ for $\mathrm{N}-\mathrm{I}$ vs $\mathrm{N}-\mathrm{N}$, logrank test. $\mathbf{b}^{\dagger} p=0.01$ for $\mathrm{A}-\mathrm{A}$ vs $\mathrm{A}-\mathrm{N}$, logrank test; $p=0.006$ for $\mathrm{N}-\mathrm{A}$ vs $\mathrm{N}-\mathrm{N}$, logrank test 
these studies relied on local measures of eGFR and albuminuria at each clinical site [38-41]; in contrast, our report used centrally measured laboratory values.

A Hong Kong study by Yang et al $[40,41]$ and, among broader populations, the Framingham Offspring study [42] and the recent Action in Diabetes and Vascular Disease: Preterax and Diamicron MR Controlled Evaluation (ADVANCE) study [38] all had similar findings to FIELD. Yang et al investigated a Chinese population with type 2 diabetes, using registry data and non-centralised outpatient laboratory measurements. However, many had CKD at baseline, and Asians with type 2 diabetes may have almost double the risk of developing end-stage kidney disease than their Europid counterparts [43]. In ADVANCE, a large trial of ACE inhibitors and intensive glucose lowering, baseline eGFR and urinary ACR were independently related to cardiovascular death, and to cardiovascular and renal events [38]. ADVANCE recruited patients from Asia, Europe, Oceania and North America, who had a history of CVD or at least one CVD risk factor. Biochemical measurements took place in non-centralised, local laboratories. In comparison, the FIELD population was predominantly Europid, and had generally lower CVD risk, and well-controlled diabetes, blood pressure and lipid levels. Furthermore, measurements were based on averaging two baseline ACR and creatinine measurements, and confirm the findings of independent effects of eGFR and albuminuria on CVD death and death from all causes.

Recently, a large observational study of Canadian outpatients also associated increased all-cause mortality rates, first hospitalisation for myocardial infarction and endstage renal disease with worsening categories of eGFR and proteinuria [39]. The FIELD trial not only confirms these findings in the context of a randomised trial of well characterised patients, but also provides greater insight, having a longer follow-up period and a greater range of endpoints, as well as using standardised measures of renal function and accounting for concurrent use of reninangiotensin system blockers. Other studies with fewer participants or more limited outcomes have also produced similar findings in type 2 diabetes. These include a South Tees, UK study of 3,288 participants [8], an Italian study of 1,538 participants [6] and the Hoorn study in the Netherlands with 631 participants [7]. In the larger Prospective Pioglitazone Clinical Trial in Macrovascular Events (PROACTIVE) study $(n=5,154)$, a post-hoc comparison of participants with eGFR more or less than $60 \mathrm{ml} \mathrm{min}{ }^{-1}$ $1.73 \mathrm{~m}^{-2}$ showed a hazard ratio of 1.25 for a composite endpoint on multivariable analysis [44]. The QRISK2 study found that $\mathrm{CKD}$ as a categorical variable added $70 \%$ to $75 \%$ cardiovascular risk [10]. In contrast, the Casale Monferrato Study did not confirm an independent association of eGFR with CVD outcomes after correction for albuminuria, possibly because of the small sample size or limited follow-up duration [5, 6]. In some of the above studies, albuminuria was not included in the analysis $[8,10]$ or not analysed as an independent variable [7, 44], and some had smaller samples than FIELD [6-8]. The independent nature of the contributions of eGFR and albuminuria in FIELD highlights that they almost certainly represent different pathological processes in type 2 diabetes [38, 39, 45].

Recent reports suggest substantial secular changes in mortality rates among patients with type 2 diabetes, as well as suggesting that CVD risk factor intervention has been extremely effective in reducing mortality and morbidity rates [46]. FIELD was a large multinational, communitybased cohort of people who had relatively uncomplicated type 2 diabetes, representing 50,169 patient-years of follow-up, and who would be estimated to lose 4 to 8 years of life expectancy [47]. By excluding most patients with pre-existing renal dysfunction and all those with $\mathrm{CKD}$ stages 4 and 5, the impact of renal disease as assessed in FIELD will have underestimated its overall contribution to CVD risk in the general population. Among those allocated to placebo, only a minority progressed to eGFR $<30 \mathrm{ml} \mathrm{min}{ }^{-1} 1.73 \mathrm{~m}^{-2}$. With too few participants deteriorating to this level prior to their first event, it was not possible to draw reliable conclusions on CVD risk in participants progressing to severe renal impairment. Furthermore, excellent control of $\mathrm{HbA}_{1 \mathrm{c}}$ throughout the study would have further reduced risk in comparison with more poorly controlled populations. The mortality rate for this cohort, around $1.4 \%$ per year at a mean entry age of 62 , was low and lower than the rates in the UK Prospective Diabetes Study (UKPDS) [18] or the Long-Term Intervention with Pravastatin in Ischemic Disease (LIPID) study [17]. In UKPDS, the myocardial infarction risk per 1,000 patient-years was 14.7 compared with 11.7 in FIELD. Other recent trials of type 2 diabetes with high usage rates of antihypertensive and lipid-lowering therapies (predominantly statins), such as the Action to Control Cardiovascular Risk in Diabetes (ACCORD) study, have also reported fewer CVD events than expected [48]. In ADVANCE, the CVD event and CVD death rates were approximately $2 \%$ and $0.9 \%$ per annum, while the acute myocardial infarction rate in an observational study of Canadian outpatients (not limited to diabetes) was $0.2 \%$ per annum $[39,49]$. The CVD, CVD death and coronary event rates of the placebo group in FIELD were $3.0 \%, 0.5 \%$ and $1.2 \%$ per annum, respectively [14]. When using the same composite endpoints for CVD as ADVANCE, the annual rate in FIELD was also $2.0 \%$.

A limitation of FIELD was that albuminuria data were only available at baseline, year 2 and study close. More frequent measures might have allowed greater accuracy in risk estimation, although the trends observed would probably have been similar. Measures of renal function 
display within-individual variation. Nevertheless, the averaging of two baseline samples would have improved the precision and also reflects real-life scenarios of risk assessment in typical clinical practice. Although we acknowledge that calculated eGFR values greater than $60 \mathrm{ml} \mathrm{min}^{-1} 1.73 \mathrm{~m}^{-2}$ are somewhat imprecise when using the MDRD 4-variable formula compared with directly measured GFR and are not recommended for clinical use, our results suggest that they have group validity in a large study: any categorical misclassification could only have weakened our conclusions. While FIELD was a selected cohort compared with community or clinic-based surveys, the latter rely on hospital discharge summaries or death certificates for outcome classification, whereas FIELD offered consistent data collection, centralised laboratory measurements and detailed central assessment and adjudication of all CVD events and deaths using extensive supporting documentation and pre-specified definitions. Furthermore, over $70 \%$ of participants screened for inclusion were recruited into the trial.

We conclude that even early stages of kidney disease in type 2 diabetes, evident from either a reduced eGFR or albuminuria, are important determinants of CVD risk and mortality rates. Additionally, renal status changes further modify CVD risk. Despite plasma creatinine and urinary ACR measurements now being part of routine care of patients with diabetes, moderate falls in eGFR are often not clinically recognised or acted upon, despite routine laboratory reporting of eGFR based on creatinine. Estimated GFR and ACR may be potentially important in redefining CVD risk and should therefore influence the clinical management of patients, especially in the assessment of CVD and renal risk, as well as in the choice, timing and evaluation of interventions to reduce those risks.

\begin{abstract}
Acknowledgements The FIELD study was supported by a grant from Laboratoires Fournier, Dijon, France and was coordinated independently by the National Health and Medical Research Council Clinical Trials Centre, University of Sydney, Sydney, NSW, Australia and overseen by the study management committee. The FIELD study was also supported by the National Health and Medical Research Council, Australia. We thank the National Heart Foundation Australia, Diabetes Australia, Diabetes New Zealand and the Finnish Diabetes Association for endorsing the study. We also thank Clinical Trials Centre staff V. Gebski and K. Byth for statistical assistance, and D. Tse and R. Pike for assistance with preparation of this manuscript. Thanks also to the many patients and investigators who enabled the study.
\end{abstract}

Duality of interest The authors declare that there is no duality of interest associated with this manuscript.

\section{References}

1. Hostetter TH (2004) Chronic kidney disease predicts cardiovascular disease. N Engl J Med 351:1344-1346
2. Levey AS, Coresh J, Balk E et al (2003) National Kidney Foundation Practice Guidelines for Chronic Kidney Disease: evaluation, classification, and stratification. Ann Intern Med 139:137-147

3. Yokoyama H, Oishi M, Kawai K, Sone H (2008) Reduced GFR and microalbuminuria are independently associated with prevalent cardiovascular disease in type 2 diabetes: JDDM study 16. Diabet Med 25:1426-1432

4. So WY, Kong AP, Ma RC et al (2006) Glomerular filtration rate, cardiorenal end points, and all-cause mortality in type 2 diabetic patients. Diab Care 29:2046-2052

5. Bruno G, Merlett F, Biggeri A et al (2005) Fibrinogen and AER are major independent predictors of 11-year cardiovascular mortality in type 2 diabetes: the Casale Monferrato Study. Diabetologia 48:427-434

6. Bruno G, Merletti F, Bargero G et al (2007) Estimated glomerular filtration rate, albuminuria and mortality in type 2 diabetes: the Casale Monferrato study. Diabetologia 50:941-948

7. Henry RM, Kostense PJ, Bos G et al (2002) Mild renal insufficiency is associated with increased cardiovascular mortality: the Hoorn Study. Kidney Int 62:1402-1407

8. Nag S, Bilous R, Kelly W, Jones S, Roper N, Connolly V (2007) All-cause and cardiovascular mortality in diabetic subjects increases significantly with reduced estimated glomerular filtration rate (eGFR): 10 years' data from the South Tees Diabetes Mortality study. Diabet Med 24:10-17

9. Valmadrid CT, Klein R, Moss SE, Klein BEK (2000) The risk of cardiovascular disease mortality associated with microalbuminuria and gross proteinuria in persons with older-onset diabetes mellitus. Arch Intern Med 160:1093-1100

10. Hippisley-Cox J, Coupland C, Vinogradova Y et al (2008) Predicting cardiovascular risk in England and Wales: prospective derivation and validation of QRISK2. BMJ 336:1475-1482

11. Colhoun HM, Lee ET, Bennett PH et al (2001) Risk factors for renal failure: the WHO Multinational Study of Vascular Disease in Diabetes. Diabetologia 44(Suppl 2):S46-S53

12. Thomas MC, Weekes AJ, Broadley OJ, Cooper ME, Mathew TH (2006) The burden of chronic kidney disease in Australian patients with type 2 diabetes (the NEFRON study). Med J Aust 185:140-144

13. MacIsaac RJ, Tsalamandris C, Thomas MC et al (2006) Estimating glomerular filtration rate in diabetes: a comparison of cystatin-C- and creatinine-based methods. Diabetologia 49:1686-1689

14. The FIELD Study Investigators (2005) Effects of long-term fenofibrate therapy on cardiovascular events in 9,795 people with type 2 diabetes mellitus (the FIELD study): randomised controlled trial. Lancet 366:1849-1861

15. The FIELD Study Investigators (2004) The need for a large scale of fibrate therapy in diabetes: the rationale and design of the Fenofibrate Intervention and Event Lowering in Diabetes (FIELD) study. Cardiovasc Diabetol 3:9

16. Vassalotti JA, Stevens LA, Levey AS (2007) Testing for chronic kidney disease: a position statement from the National Kidney Foundation. Am J Kidney Dis 50:169-180

17. LIPID Study Group (2002) Long-term effectiveness and safety of pravastatin in 9,014 patients with coronary heart disease and average cholesterol concentrations: the LIPID trial follow-up. Lancet 359:1379-1387

18. Turner RC, Holman RR, Cull CA et al (1998) Intensive bloodglucose control with sulphonylureas or insulin compared with conventional treatment and risk of complications in patients with type 2 diabetes (UKPDS 33). Lancet 352:837-853

19. Patel A (2007) Effects of a fixed combination of perindopril and indapamide on macrovascular and microvascular outcomes in patients with type 2 diabetes mellitus (the ADVANCE trial): a randomised controlled trial. Lancet 370:829-840 
20. Levey AS, Bosch JP, Lewis JB, Greene T, Rogers N, Roth D (1999) A more accurate method to estimate glomerular filtration rate from serum creatinine: a new prediction equation. Ann Intern Med 130:461-470

21. Heerspink HJL, Brinkman JW, Bakker SJL, Gansevoort RT, de Zeeuw D (2006) Update on microalbuminuria as a biomarker in renal and cardiovascular disease. Curr Opin Nephrol Hypertens 15:631-636

22. Harrell FE (2001) Regression modelling strategies. Springer, New York

23. Kuk AYC (1984) All subsets in proportional hazards models. Biometrika 71:587-592

24. Vaziri ND, Navab M, Fogelman AM (2010) HDL metabolism and activity in chronic kidney disease. Nat Rev Nephrol 6:287-296

25. Vaziri ND (2006) Dyslipidemia of chronic renal failure: the nature, mechanisms, and potential consequences. Am J Physiol Renal Physiol 290:F262-F272

26. McCullough PA, Verrill TA (2010) Cardiorenal interaction: appropriate treatment of cardiovascular risk factors to improve outcomes in chronic kidney disease. Postgrad Med 122:25-34

27. Arici M, Walls J (2001) End-stage renal disease, atherosclerosis, and cardiovascular mortality: Is $\mathrm{C}$-reactive protein the missing link? Kidney Int 59:407-414

28. Himmelfarb J, Stenvinkel P, Ikizler TA, Hakim RM (2002) The elephant in uremia: oxidant stress as a unifying concept of cardiovascular disease in uremia. Kidney Int 62:1524-1538

29. Sarnak MJ, Levey AS, Schoolwerth AC et al (2003) Kidney disease as a risk factor for development of cardiovascular disease: a statement from the American Heart Association Councils on Kidney in Cardiovascular Disease, High Blood Pressure Research, Clinical Cardiology, and Epidemiology and Prevention. Circulation 108:2154-2169

30. Shlipak MG, Heidenreich PA, Noguchi H, Chertow GM, Browner WS, McClellan MB (2002) Association of renal insufficiency with treatment and outcomes after myocardial infarction in elderly patients. Ann Intern Med 137:555-562

31. Wright RS, Reeder GS, Herzog CA et al (2002) Acute myocardial infarction and renal dysfunction: a high-risk combination. Ann Intern Med 137:563-570

32. Peter AM, Keisha RS, Steven B, Michael PH, Mukesh G, Harold JM (2002) Benefits of aspirin and beta-blockade after myocardial infarction in patients with chronic kidney disease. Am Heart J 144:226-232

33. Stehouwer CA, Zeldenrust GC, den Ottolander GH, Hackeng WHL, Donker AJM, Nauta JJP (1992) Urinary albumin excretion, cardiovascular disease, and endothelial dysfunction in noninsulin-dependent diabetes mellitus. Lancet 340:319-323

34. Stehouwer CDA, Lambert J, Donker AJM, van Hinsbergh VWM (1997) Endothelial dysfunction and pathogenesis of diabetic angiopathy. Cardiovasc Res 34:55-68
35. Festa A, D'Agostino R Jr, Howard G, Mykkanen L, Tracy RP, Haffner SM (2000) Inflammation and microalbuminuria in nondiabetic and type 2 diabetic subjects: the Insulin Resistance Atherosclerosis Study. Kidney Int 58:1703-1710

36. Wilson PWF, D'Agostino RB, Levy D, Belanger AM, Silbershatz H, Kannel WB (1998) Prediction of coronary heart disease using risk factor categories. Circulation 97:1837-1847

37. Uhlig K, Levey AS, Sarnak MJ (2003) Traditional cardiac risk factors in individuals with chronic kidney disease. Semin Dial $16: 118-127$

38. Ninomiya T, Perkovic V, de Galan B et al (2009) Albuminuria and kidney function independently predict cardiovascular and renal outcomes in diabetes. J Am Soc Nephrol 20:1813-1821

39. Hemmelgarn BR, Manns BJ, Lloyd A et al (2010) Relation between kidney function, proteinuria, and adverse outcomes. JAMA 303:423-429

40. Yang X, So WY, Tong PCY et al (2008) Development and validation of an all-cause mortality risk score in type 2 diabetes: the Hong Kong Diabetes Registry. Arch Intern Med 168:451457

41. Yang X, So W-Y, Kong APS et al (2008) Development and validation of a total coronary heart disease risk score in type 2 diabetes mellitus. Am J Cardiol 101:596-601

42. Foster MC, Hwang S, Larson MG et al (2007) Cross-classification of microalbuminuria and reduced glomerular filtration rate. Arch Intern Med 167:1386-1392

43. Young BA, Maynard C, Boyko EJ (2003) Racial differences in diabetic nephropathy, cardiovascular disease, and mortality in a national population of veterans. Diab Care 26:2392-2399

44. Schneider CA, Ferrannini E, DeFronzo R, Schernthaner G, Yates J, Erdmann E (2008) Effect of pioglitazone on cardiovascular outcome in diabetes and chronic kidney disease. J Am Soc Nephrol 19:182-187

45. Retnakaran R, Cull CA, Thorne KI, Adler AI, Holman RR, UKPDS Study Group (2006) Risk factors for renal dysfunction in type 2 diabetes. UKPDS 74. Diabetes 55:1832-1839

46. Charlton JMSC, Latinovic RBSC, Gulliford MCF (2008) Explaining the decline in early mortality in men and women with type 2 diabetes: a population-based cohort study. Diabetes Care 31:1761-1766

47. Gu K, Cowie CC, Harris MI (1998) Mortality in adults with and without diabetes in a national cohort of the U.S. population, 19711993. Diabetes Care 21:1138-1145

48. Goff DC Jr, Gerstein HC, Ginsberg HN et al (2007) Prevention of cardiovascular disease in persons with type 2 diabetes mellitus: current knowledge and rationale for the Action to Control Cardiovascular Risk in Diabetes (ACCORD) trial. Am J Cardiol 99:S4-S20

49. The ADVANCE Collaborative Group (2008) Intensive blood glucose control and vascular outcomes in patients with type 2 diabetes. N Engl J Med 358:2560-2572 